\title{
Optimalisasi satuan lalu lintas Polres Gresik dalam menanggulangi kecelakaan lalu lintas akibat pelanggaran muatan
}

\section{Optimization of traffic Gresik traffic units in treating traffic accidents in consequences of violation of load}

\author{
I Made Parwita \\ Program Studi Magister Kajian Ilmu Kepolisian, Sekolah Pascasarjana, Universitas Airlangga \\ Surabaya, 60286, Jawa Timur, Indonesia \\ E-mail: i.made.parwita@pasca.unair.ac.id
}

\begin{abstract}
Abstrak
Penelitian ini bertujuan untuk mengoptimalisasi satuan lalu lintas untuk menanggulangi kecelakaan akibat pelanggaran muatan. Metode yang digunakan yakni penelitian kualitatif. Hasil penelitian menunjukkan bahwa langkah-langkah yang telah dilakukan satuan lalu lintas Polres Gresik dalam menanggulangi kecelakaan yang disebabkan kelebihan muatan adalah langkah preemtif (berupa sosialisasi), preventif (perencanaan rekayasa lalu lintas, perencanaan kawasan tertib lalu lintas) dan langkah represif (penilangan dan melaksanakan operasi gabungan). Kendala yang dihadapi oleh Polres Gresik dalam mengoptimalkan satuan lalu lintas Polres Gresik dalam menanggulangi kecelakaan yang disebabkan kelebihan muatan adalah minimnya kesadaran pengemudi yang mementingkan pendapatan daripada keselamatan lalu lintas, kurang tegasnya anggota dalam menindak pelanggar kelebihan muatan, pelanggaran waktu beroperasi kendaraan yang terjadi secara berpola, kurangnya kerjasama dari Dinas Perhubungan dan kendala penempatan barang bukti. Upaya optimalisasi satuan lalu lintas Polres Gresik dalam menanggulangi kecelakaan lalu lintas yang disebabkan kelebihan muatan adalah memaksimalkan sosialisiasi tata cara pengangkutan yang benar kepada para pengusaha pemilik barang, transporter dan pengemudi yang bekerjasama dengan dinas perhubungan Kabupaten Gresik, melakukan sosialisasi pentingnya melakukan pengujian kendaraan bermotor, bekerjasama dengan pihak asuransi kendaraaan untuk menghilangkan asuransi kecelakaan akibat pelanggaran muatan, dan memaksimalkan rekayasa lalu lintas untuk melakukan penataan moda share material.
\end{abstract}

Kata kunci: kecelakaan; kurangnya fasilitas; sosialisasi; rekayasa; penilangan

\begin{abstract}
This study aims to optimize the traffic unit to overcome accidents caused by cargo violations. The method used is qualitative research. The results showed that the steps taken by the Gresik Police Traffic Unit in overcoming accidents caused by overload were preemtive steps (in the form of socialization), preventive (traffic engineering planning, traffic orderly area planning) and repressive steps (crossing and implementing joint operations). The obstacles faced by the Gresik Resort Police in optimizing the traffic units in handling the accidents caused by overloading are the lack of awareness of drivers who are concerned with revenue rather than traffic safety, the lack of clarity in members acting against overload offenders, violations of vehicle operating time that occur patternedly, lack of cooperation from the Transportation Agency and obstacles in the placement of evidence. Efforts to optimize the traffic unit of the Gresik Regional Police in overcoming traffic accidents caused by overloading are maximizing the dissemination of proper transportation procedures to business owners of goods, transporters and drivers who work closely with the transportation service office in Gresik Regency, to socialize the importance of carrying out motorized vehicle testing, in cooperation with vehicle insurance to eliminate accident insurance due to cargo violations, and maximize traffic engineering to arrange material share modes.
\end{abstract}

Keywords: accident; lack of facilities; socialization; manipulation; crossing

\section{Pendahuluan}

Kecelakaan merupakan salah satu kejadian naas di jalanan. Selain kondisi kendaraan yang tidak layak jalan, ada faktor lain yang dapat menyebabkan kecelakaan di jalan raya diantaranya kurangnya fasilitas jalan raya sebagai akses utama untuk kegiatan pertambangan harus menjadi perhatian khusus serta 
kelebihan muatan. Tidak hanya menyebabkan kecelakaan, muatan yang berlebihan dari kapasitas normal akan membuat umur kendaraan berkurang dan membuat fasilitas terutama jalan raya cepat rusak, sopir yang mengalami kelebihan muatan akan bersiko tinggi (Chang \& Mannering 1999; Khorashadi et al 2005; McKinnon 2008). Seharusnya sopir yang membawa muatan lebih memperhatikan jumlah muatannya, karena setiap tipe mobil memiliki batas maksimum muatan. Selaras dengan kasus terbaru yang dihimpun dari koran Surya pada tanggal 9 November 2017 (Surya.co.id. 16 Desember 2017), menjelaskan bawah truk bermuatan balok kayu terguling dan 2 orang pengendara sepeda motor terluka, tepatnya di jalan lingkar terminal Bunder. Jika hal ini diabaikan akan berakibat pada kecelakaan dijalan raya.

\section{Metode Penelitian}

Peneliti menggunakan metode penelitian kualitatif untuk menentukan cara mencari, mengumpulkan, mengolah dan menganalisis data hasil penelitian tersebut. Langkah preemtif untuk menanggulangi kecelakaan yang disebabkan kelebihan muatan adalah suatu langkah yang dilakukan untuk mengantisipasi adanya kecelakaan kegiatan Satlantas Polres Gresik pada langkah ini adalah ditunjukan dalam gelar acara secara besar untuk mempromosikan tertib berlalu lintas, yang mana ada kerjasama dengan masyarakat. Untuk menarik perhatian masyarakat dengan ada inisiatif melaksanakan gelar acara sosialisasi mengenai tertib lalu lintas yang dilakukan. Informan penelitian yang diperoleh yaitu:

Tabel 1.

Informan penelitian

\begin{tabular}{ll}
\hline Nama & Keterangan \\
\hline Wahyu S. Bintoro & Kapolres Gresik \\
Yossy Eka Prasetya Suwandana & Kanit Laka Lantas \\
Wiji mulyono & Satlantas Polres Gresik \\
Rury Dibyo & Satlantas Polres Gresik \\
Hamdi Rozi & Tersangka sopir truk muatan di Gresik \\
Nanang Setiawan & Kadishub Kabupaten Gresik \\
M. Ghofar & Tersangka sopir truk muatan di Gresik \\
Gunawan & Komunitas Sopir Truk Muatan di Gresik \\
Samsudin & Saudara Korban \\
Dewi Murni & Korban kecelakaan \\
\hline
\end{tabular}

Sumber: Data primer peneliti

Teknik pengumpulan data yang digunakan dalam penelitian ini yakni dengan cara wawancara dan observasi. Sementara itu, analisis data dilakukan dari hasil wawancara, catatan lapangan, dan dokumentasi, dengan cara mengorganisasikan data ke dalam kategori, menjabarkan ke dalam unit-unit, melakukan sintesa, menyusun ke dalam pola, memilih mana yang penting dan yang akan dipelajari, dan membuat kesimpulan sehingga mudah dipahami oleh diri sendiri dan orang lain (Sugiyono 2009). Komponen dalam analisis data adalah sebagai berikut reduksi data, penyajian data serta penyimpulan data.

\section{Hasil dan Pembahasan}

\section{Langkah-langkah Satuan Lalu Lintas Polres Gresik dalam menanggulangi kecelakaan lalu lintas}

Gelar sosialisasi yang dilaksanakan oleh Polres Gresik, Babinkamtibmas, Babinsa dan pemerintah desa/kelurahan setempat dapat diterima oleh masayarakat, kemudian pesan mengenai agar meningkatkan budaya berlalu lintas pun dapat diterima dengan baik, di mana sosialisasi tersebut mengenai perilaku tertib berlalu lintas, seperti pemakaian helm ber-SNI, motor tidak dimodifikasi sehingga menghilangkan 
fungsi-fungsi lalu lintas dan lain sebagainya terutama bagi supir truck mengenai beban muatan kendaraan angkutan. Kemudian sosialisasi juga dilaksanakan pada lingkungan pelajar, karyawan dan instansiinstansi pemerintah dan swasta dan instansi-instansi pemerintah serta memberikan Pelatihan Penanggulangan Gawat Darurat (PPGD) pada masyarakat di jalur black spot atau rawan kecelakaan lalu lintas. Pendekatan preemtif ini, sangat penting untuk dikedepankan mengingat pencegahan secara dini melalui optimalisasi kegiatan-kegiatan bidang edukatif masih dirasa sangat perlu dan penting untuk terus dilaksanakan.

\section{Langkah preventif}

Satlantas Polres melakukan perencanaan rekayasa lalu lintas yang bertujuan untuk mengatasi permasalahan lalu lintas yang terjadi seperti kurangnya rambu-rambu lalu lintas pada daerah tertentu, jalanan licin, jalan rusak, kemacetan lalu lintas dan lain-lain (Lee 2014; Qi et al 2015). Kegiatan rekayasa lalu lintas yang dilakukan yaitu mengalihkan arus lalu lintas kejalan alternatif diantaranya kendaran kecil di alihkan ke jalan alternatif sedangkan kendaraan besar seperti bus dan truk serta kendaraan pengangkut lainnya. Ini sesuai UU No.2 Tahun 2002 tentang Polri, UUNo.22 Tahun 2009 tentang Lalu Lintas Angkutan Jalan, Perkap No.10 Tahun 2012 Tentang Lalu Lintas dan Jalan. Salah satu cara Satlantas Polres Gresik menangani lalu lintas di Kabupaten Gresik adalah dengan cara melakukan sebuah rekayasa lalu lintas.

Perencanaan Kawasan Tertib Lalu Lintas, menurut Peraturan Bupati Gresik Nomor 5 Tahun 2011 tanggal 25 Januari 2011 Tentang Kawasan Tertib Lalu Lintas, Kawasan Tertib Lalu Lintas adalah suatu ruas jalan/koridor/wilayah tertentu yang disepakati oleh instansi terkait dibidang lalu lintas sebagai proyek percontohan ketertiban lalu lintas, baik bagi aparat terkait dalam menjalankan tugas sesuai kewenangan masing-masing secara terpadu maupun bagi pengguna jalan dalam memanfaatkan jalan sesuai dengan peruntukannya, sehingga lalu lintas dan angkutan jalan dapat terselenggara secara selamat, aman, lancar, nyaman dan efisien (Pasal 1, huruf e).

Satlantas memiliki peran yang kompleks dalam pengaturan lalu lintas di Kabupaten Gresik untuk memberi keamanan dan kenyamanan serta memastikan angka kecelakaan di Kabupaten Gresik menurun dan memberi pendidikan berlalu lintas kepada masyarakat. Di wilayah Kabupaten Gresik ada beberapa kawasan tertib lalu lintas yang diterapkan, yaitu di sepanjang jalan Veteran (2,74 KM), jalan. R.A Kartini (1,63 KM) dan Jalan Dr. Wahidin Sudirohusodo (4,94 KM).

\section{Langkah represif}

Penilangan dalam praktiknya penanganan kasus pelanggaran pengendara kendaraan bermotor jenis apapun, baik roda dua maupun roda empat, aparat kepolisian umumnya melakukan penindakan (tilang), upaya ini disebut dengan upaya represif (Trinca 1988; WHO 2004; OECD 2008; Johnston 2010). Salah satu upaya lainnya yang dilakukan oleh Polres Gresik dalam terjadinya pelanggaran muatan adalah dengan tindakan penilangan. Salah satu tugas yang dibebankan kepada kepolisian adalah penanganan permasalahan lalu lintas baik yang bersifat prefentif maupun represif. Maka dari itu kepolisian dituntut untuk menjaga ketertiban lalu lintas selain juga harus menegakkan hukum pidana lalu lintas (Bliss \& Breen 2009).

Di samping itu, Satlantas Polres Gresik juga melaksanakan operasi gabungan, dilakukan secara bersamasama dengan instansi terkait yaitu Dishub dan Polres Gresik. Dinas Perhubungan Kabupaten Gresik dan Polres Gresik menggelar operasi kelengkapan surat-surat kendaraan dan kelengkapan uji KIR. Tim gabungan langsung meminta sopir-sopir truk dan mobil pick up yang melintas, dimana dari surat-surat kelengkapan kendaraan diperiksa Surat Izin Mengemudi (SIM) dan uji KIR kendaraan. 


\section{Kendala Satuan Lalu Lintas Polres Gresik dalam menanggulangi kecelakaan yang disebabkan kelebihan muatan}

Salah satu contoh berdasarkan kasus yang terjadi di Jalan Veteran Kebomas Gresik, dengan kategori pada pelanggaran tingkat III karena pengangkutan barang dengan kelebihan muatan mencapai 25\%. Yang mengakibatkan kecelakaan beruntun pada sepuluh kendaraan bermotor baik R4 dan R2, yang mana tersangka melakukan pelanggaran muatan karena alasan mementingkan pendapatan (kejar setoran), dan efisiensi/ hemat biaya akomodasi. Pada hakekatnya sistem kejar setoran ini, sama halnya dengan sistem penggajian untuk para supir truk, di mana para supir harus mengejar target tertentu untuk mencapai penghasilan atau pendapatan yang maksimal. Akan tetapi, akibat sistem tersebut, dampak yang terjadi adalah perilaku supir di jalan yang tidak disiplin dan tidak tertib.

Hasil penelitian lain juga membuktikan sebagai berikut, yaitu kajian empiris Nyamuame, et al (2015) yang menemukan bahwa hal yang paling banyak menyebabkan kecelakaan lalu lintas adalah karena kecepatan yang meningkat, kelebihan kapasitas muatan dan mengabaikan rambu lalu lintas atau peraturan yang telah ditetapkan dalam hal berlalu lintas oleh pemerintah sehingga rawan macet dan kecelakaan. Penelitian Hartono dkk, menjelaskan bahwa pengaruh kejar setoran dan perilaku tertib lalu lintas sangat erat. Dalam kesehariannya, kejar setoran ini memberikan pengaruh yang buruk terhadap perilaku para supir angkot pada saat mengemudi. Perilaku dan kebiasaan buruk yang sering dilakukan supir angkot antara lain: melanggar rambu-rambu lalu lintas, berhenti mendadak, mengetem di sembarang tempat, memotong jalan tanpa memberi isyarat, dan mengisi muatan armada secara berlebihan. Hal-hal tersebut sangatlah mengganggu pengguna jalan lain serta menyebabkan kemacetan dan ketidaknyamanan berlalu lintas.

Polres Gresik telah melakukan langkah-langkah untuk menanggulangi kecelakaan lalu lintas di antaranya adalah melakukan sosialisasi mengenai tertib lalu lintas khusunya pada pengemudi truk kendaraan muatan di Kabupaten Gresik. Namun, hal ini masih dirasa kurang maksimal jika anggota Polres Gresik dalam menindak pelanggar kelebihan muatan masih dinilai kurang tegas. Sikap dari petugas Polres Gresik sangat berpengaruh dalam menindak pelanggar kelebihan muatan. Apabila petugas memiliki sikap yang baik maka dia akan dapat menjalankan tugasnya dengan baik seperti apa yang diinginkan oleh pembuat kebijakan, sebaliknya apabila sikapnya tidak mendukung maka implementasi tindakan tidak akan terlaksana dengan baik. Tindakan Polres Gresik yang dinilai kurang tegas tersebut, sesuai dengan penelitian Oktavania (2014) yang menyatakan bahwa kurangnya pengendalian, pengawasan, dan komunikasi penindak pelanggar lalu lintas, menyebabkan kecelakaan lalu lintas yang berkepanjangan. Kendala yang dihadapi terutama minimnya kualitas koordinasi sesama petugas, sehingga membuat kinerja dari Unit Pelaksana Teknis Lalu Lintas dan Angkutan Jalan (UPT LLAJ) kurang maksimal.

Salah satu penelitian membuktikan bahwa penyebab kemacetan lalu lintas di ruas jalan adalah adanya aktivitas pada jam dan waktu bersamaan, sehingga menimbulkan kemacetan lalu lintas. Kemudian, sistem rambu-rambu lalu-lintas disepanjang jalan pun kurang mendapat perhatian lebih, seperti lampu rambu lalu lintas yang tak berfungsi, tidak ada temapat parkir serta truk-truk besar dengan beban muatan yang berlebihan, akibatnya tumbuh hambatan dan kecelakaan lalu lintas (Muchlisin \& Lubis, 2016). Lalu lintas pada umumnya terhambat pada pola tertentu, seperti pada jam pulang dan berangkat seolah serta kerja. Gambaran jalan yang sempit, kemudian tidak tersedia tempat parkir, hingga masalah ketidak-patuhan masyarakat terhadap tertib lalu lintas, masih menjadi penyebab rawan kecelakaan lalu lintas dan kemacetan di wilayah hukum Polres Gresik. Kemudian permasalahan-permasalahan kemacetan lainnya yang sering kali ditemukan adalah terkait dengan tingkat kepadatan arus lalu lintas pada jalan, pengadaan sarana dan prasarana jalan kurang memadai, belum berfungsinya ruas jalan dan trotoar sebagaimana mestinya. Sesuai dengan Perbup nomor 21 Tahun 2001 tentang Pengaturan Waktu Operasi Kendaraan Angkutan Barang menjelaskan bahwa waktu operasi kendaraan angkutan barang antara pukul 09.00 hingga 14.00 WIB, dan pukul 21.00 sampai 05.00 WIB dengan muatan sumbu terberat (MST) 8 ton. 
Namun dalam kenyataannya masih ada beberapa kendaraan muatan barang yang melintas pada jam 08.00 pagi atau jam 15.00. Hal tersebut merupakan salah satu pelanggaran yang berpotensi menimbulkan kecelakaan.

Kerjasama antara stakeholder pada umunya telah membuka peluang bagi pemerintah daerah untuk mengembangkan kebijakan lokal secara bijaksana karena fakta di lapangan membuktikan bahwa implementasi kebijakan daerah masih mengalami hambatan dan kendala dan pelaksaannya belum maksimal diterapkan karena keberadaan daerah-daerah otonom baru tidak diiringi dengan kapasitas sumber daya manusia dan finansial yang memadai. Dengan demikian banyak terjadi keterlambatan dalam pembangunan terutama pembangunan infrastruktur, seperti kebutuhan untuk tertib lalu lintas. Oleh karena itu, pemerintah daerah perlu mencari solusi atas persoalan tersebut dengan melibatkan berbagai stakeholder terkait dalam pelaksanaan pembangunan.

Menurut Edward III mengemukakan kecenderungan-kecenderungan atau disposisi merupakan salah-satu faktor yang mempunyai konsekuensi penting bagi implementasi kebijakan yang efektif. Jika para pelaksana mempunyai kecenderungan atau sikap positif atau adanya dukungan terhadap implementasi kebijakan maka terdapat kemungkinan yang besar implementasi kebijakan akan terlaksana sesuai dengan keputusan awal. Demikian sebaliknya, jika para pelaksana bersikap negatif atau menolak terhadap implementasi kebijakan karena konflik kepentingan maka implementasi kebijakan akan menghadapi kendala yang serius. Sikap disposisi pelaksana dapat menjadi kendala bagi implementasi program Kawasan Tertib Lalu Lintas di Gresik. Pada umumnya, bentuk penolakan dapat bermacam-macam seperti yang dikemukakan Edward III tentang zona ketidakacuhan dimana para pelaksana kebijakan melalui keleluasaannya (diskresi) dengan cara yang halus menghambat implementasi kebijakan dengan cara mengacuhkan, menunda dan tindakan penghambatan lainnya.

Sikap penerimaan atau penolakan dari agen pelaksana kebijakan sangat mempengaruhi keberhasilan atau kegagalan implementasi kebijakan publik. Hal ini sangat mungkin terjadi karena kebijakan yang dilaksanakan bukanlah hasil formulasi warga setempat yang mengenal betul permasalahan dan persoalan yang mereka rasakan. Tetapi kebijakan publik biasanya bersifat top down yang sangat mungkin para pengambil keputusan tidak mengetahui bahkan tak mampu menyentuh kebutuhan, keinginan atau permasalahan yang harus diselesaikan.

Faktor komunikasi kebijakan yang dilakukan tidak mengenai semua sasaran (target group). Selain dari itu, tidak adanya komunikasi/koordinasi yang baik antar sumber-sumber yang terlibat dalam implementasi kebijakan (aparat pelaksana) dalam hal pengawasan, pengaturan dan pengadaan infrastuktur serta kurangnya respon antara pelaksana kebijakan dalam melaksanakan penanganan kecelakaan akibat muatan.

Salah satu kendala dalam menanggulangi kecelakaan lalu lintas akibat pelanggaran muatan adalah penempatan barang bukti yang notabenenya kendaraan besar. Barang bukti merupakan syarat sah pidana, dan salah satu kendala dalam menanggulangi kecelakaan lalu lintas akibat pelanggaran muatan di Kabupaten Gresik adalah penempatan barang bukti yang wujudnya merupakan kendaraan besar.

\section{Upaya optimalisasi Satuan Lalu Lintas Polres gresik dalam menanggulangi kecelakaan lalu lintas yang disebabkan kelebihan muatan}

Upaya optimalisasi satuan lalu lintas Polres Gresik dalam menanggulangi kecelakaan lalu lintas, yaitu salah satunya dengan memaksimalkan sosialisasi tata cara pengangkutan yang benar kepada para pengusaha pemilik barang, transporter dan pengemudi yang mana melakukan kerja sama dengan Dinas Perhubungan Gresik. Masih diperlukan memaksimalkan sosialisasi tata cara pengangkutan yang benar 
kepada para pengusaha pemilik barang, transporter dan pengemudi yang mana melakukan kerja sama dengan Dinas Perhubungan Kabupaten Gresik.

Salah satu fungsi pelayanan publik yang dilaksanakan oleh Dinas Perhubungan Komunikasi dan Informatika (Dinhubkominfo) Kabupaten Gresik adalah melaksanakan pelayanan pengujian kendaraan bermotor. Kendala yang masih dihadapi oleh Dishub dan Polres Gresik dalam menanggulangi pelanggaran muatan adalah masih banyak kendaraan yang tidak melakukan pengujian kendaraan bermotor (uji kir). Tujuan uji kir salah satunya adalah untuk menjamin keselamatan secara teknis terhadap pengguna angkutan umum, dan menjamin kelaikan teknis kendaraan untuk beroperasi (Pratama 2015; Hirawan 2017). Terjadinya kecelakaan akibat pelanggaran muatan di wilayah hukum Polres Gresik, diakibatkan salah satunya karena kendaraan tidak melakukan pengujian KIR. Di sini perlu disosialisasikan bahwa Pengujian Kendaraan Bermotor dilakukan Setiap 6 bulan sekali dan apabila terlambat melaksanakan uji Kir dikenakan denda sebesar 2\% dari pokok retribusi (Negara et al 2017; Farida et al 2019). Untuk optimalisasi pengujian kendaraan bermotor harus dilengkapi dengan fasilitas dan peralatan pengujian dengan pemilihan jenis, tipe, kapasitas, jumlah, dan teknologi peralatan pengujian harus dilakukan secara cermat dan tepat. Pengujian pun harus dilakukan oleh tenaga penguji yang memiliki kualifikasi teknis tertentu dan sesuai dengan prosedur dan tata cara, serta dilaksanakan di lokasi yang telah ditetapkan (Hermawan et al 2013; Jayanti \& Widjasena 2016). Selain itu hasil uji berkala kendaraan bermotor harus akurat dan dapat dipertanggungjawabkan sehingga fasilitas dan peralatan pengujian harus dipelihara atau dirawat secara periodik melalui kalibrasi.

Pada umumnya, PT Jasa Raharja (Persero) sebagai BUMN yang menangani masalah asuransi atau jaminan kecelakaan lalu lintas, siap untuk memberikan bantuan jika ada warga yang mengalami kecelakaan lalu lintas di jalan raya. Akan tetapi, hal ini perlu menjadi strategi baru sebagai cara untuk mengurangi pelanggar muatan di Kabupaten Gresik. Polres Gresik dapat mengajukan saran dan melakukan kerjasama dengan jasa asuransi mengenai klaim asuransi pengemudi pelanggar muatan, dimana tidak ada asuransi kecelakaan bagi pengemudi yang sengaja melanggar berat muatan, sehingga menimbulkan efek jera. Besaran klaim atau santunan yang diberikan untuk masing-masing korban kecelakaan sebesar Rp 20 juta dan maksimal Rp 50 juta jika meninggal dunia. Klaim asuransi pasti diberikan apa pun alasan penyebab kecelakaannya. Baik karena murni kecelakaan atau pun karena kelalaian. Kecelakaan yang tidak mendapatkan klaim hanya berlaku bagi kecelakaan tunggal. Kecelakaan tunggal tidak termasuk dalam daftar korban yang ditanggung oleh Jasa Raharja, namun ada kebijakan memberikan santunan terhadap korban kecelakaan maupun meninggal, namun besarannya disesuaikan dengan kebijakan. Harapan bagi kebijakan atas tidak ada klaim bagi pelanggar muatan, ini diyakini dapat memberi efek jera bagi pengemudi tersebut.

Rekayasa lalu lintas merupakan suatu penanganan yang berkaitan dengan perencanaan, perancangan dan operasi lalu lintas jalan serta jaringannya, agar menjaga keamanan, kenyamanan serta ketertiban lalu lintas. Rekayasa lalu lintas yang dilakukan biasanya terjadi di beberapa ruas jalan atau faktor lainnya, diantaranya: pertama, Jalan simpang, persimpangan menjadi simpul pada jaringan jalan dimana ruas jalan akan bertemu dan lintasan arus kendaraan berpotongan. Lalu lintas pada setiap persimpangan akan secara bersama-sama dengan lalu lintas lainnya. Persimpangan juga dianggap sebagai salah satunya timbulnya konflik antara kendaraan dengan kendaraan lain yang jika dibiarkan akan menimbulkan kecelakaan. Kedua, jalan satu arah, sebagai pola lalu lintas yang dilakukan dengan merubah jalan dua arah menjadi satu arah yang berfungsi untuk meningkatkan keselamatan dan kapasitas jalan dan persimpangan sehingga meningkatkan kelancaran lalu lintas. Ketiga, kapasitas jalan, yaitu jumlah kendaraan maksimum yang dimiliki dengan kemungkinan yang cukup untuk melewati rusa jalan tersebut. Rekayasa lalu lintas harus disesuaikan jenis barang, kalau material ringan maka akan melewati jalan-jalan KTL, jika berat maka akan dialihkan melalui jalan lain. Sehingga beban jalan raya terbagi antara jalan nasional, jalan propinsi, jalan kabupaten dapat berkurang dengan adanya pembagian tersebut. 
Kemampuan ruas jalan untuk menampung arus atau volume lalu lintas yang ideal dalam satuan waktu tertentu, dinyatakan dalam jumlah kendaraan yang melewati potongan jalan tertentu dalam satu jam (kend/jam), atau dengan mempertimbangan berbagai jenis kendaraan yang melalui suatu jalan digunakan satuan mobil penumpang sebagai satuan kendaraan dalam perhitungan kapasitas maka kapasitas menggunakan satuan satuan mobil penumpang perjam. Pada saat arus rendah kecepatan lalu lintas kendaraan bebas tidak ada gangguan dari kendaraan lain, semakin banyak kendaraan yang melewati ruas jalan, kecepatan akan semakin turun sampai suatu saat tidak bisa lagi arus/volume lalu lintas bertambah, di sinilah kapasitas terjadi. Setelah itu arus akan berkurang terus dalam kondisi arus yang dipaksakan sampai suatu saat kondisi macet total, arus tidak bergerak dan kepadatan tinggi. Oleh karena itu, untuk menyiasati dan menghindari kecelakaan yang diakibatkan truk pengangkut barang muatan, maka dibutuhkan rekayasa lalu lintas melalui share moda material melalui berbagai jalan raya yang merata. Sehingga beban jalan raya terbagi antara jalan nasional, jalan propinsi, jalan kabupaten dapat berkurang dengan adanya pembagian tersebut.

\section{Simpulan}

Langkah-langkah yang telah dilakukan satuan lalu lintas Polres Gresik dalam menanggulangi kecelakaan yang disebabkan kelebihan muatan adalah langkah preemtif (berupa sosialisasi), preventif (perencanaan rekayasa lalu lintas, perencanaan kawasan tertib lalu lintas) dan langkah represif (penilangan dan melaksanakan operasi gabungan).

Kendala yang dihadapi oleh Polres Gresik dalam mengoptimalkan satuan lalu lintas Polres Gresik dalam menanggulangi kecelakaan yang disebabkan kelebihan muatan adalah minimnya kesadaran pengemudi yang mementingkan pendapatan daripada keselamatan lalu lintas, kurang tegasnya anggota dalam menindak pelanggar kelebihan muatan, pelanggaran waktu beroperasi kendaraan yang terjadi secara Berpola, kurangnya kerjasama dari Dinas Perhubungan dan kendala penempatan barang bukti.

Upaya optimalisasi satuan lalu lintas Polres Gresik dalam menanggulangi kecelakaan lalu lintas yang disebabkan kelebihan muatan adalah memaksimalkan sosialisiasi tata cara pengangkutan yang benar kepada para pengusaha pemilik barang, transporter dan pengemudi yang bekerja sama dengan dinas perhubungan Kabupaten Gresik, melakukan sosialisasi pentingnya melakukan pengujian kendaraan bermotor, bekerjasama dengan pihak asuransi kendaraaan untuk menghilangkan asuransi kecelakaan akibat pelanggaran muatan, dan memaksimalkan rekayasa lalu lintas untuk melakukan penataan moda share material.

\section{Daftar Pustaka}

Bliss T \& Breen J (2009) Implementing the Recommendations of the World Report on Road Traffic Injury Prevention. Country Guidelines for the Conduct of Road Safety Capacity Reviews and the Related Specification of Lead Agency Reforms, Investment Strategies and Safety Projects. World Bank Global Road Safety Facility, Washington, DC.

Chang LY \& Mannering F (1999) Analysis of injury severity and vehicle occupancy in truck-and nontruck-involved accidents. Accident Analysis \& Prevention, 31 (5):579-592.

Hermawan SA, Haryadi B, \& Kushardjoko W (2013) Hubungan Uji Berkala Kendaraan Bermotor dengan Kecelakaan Lalu Lintas di Kota Cirebon (Doctoral dissertation, Civil Engineering Master Program). Universitas Diponegoro. Semarang.

Hirawan Z (2017) Pelayanan publik di Kabupaten Subang (Studi kasus pelayanan uji kir dan trayek pada Dinas Perhubungan Kabupaten Subang). Jurnal Administrasi Publik 8 (1). 
Jayanti S \& Widjasena B (2016) Analisis penyebab dan pengendalian kejadian kecelakaan kerja di jalan raya pada deliveryman tahun 2014-2015 (Studi kasus pada deliveryman PT. Coca Cola Amatil Indonesia Central Java). Jurnal Kesehatan Masyarakat (e-Journal) 4 (4):756-762.

Johnston I (2010) Beyond "best practice" road safety thinking and systems management - A case for culture change research. Safety Science 48 (9):1175-1181. doi:10.1016/j.ssci.2009.12.003

Khorashadi A, Niemeier D, Shankar V, \& Mannering F (2005) Differences in rural and urban driverinjury severities in accidents involving large-trucks: An exploratory analysis. Accident Analysis \& Prevention 37 (5):910-921. doi:10.1016/j.aap.2005.04.009

Lee EH (2014) U.S. Patent Application No. 14/346,758.

McKinnon AC (2008) Should the maximum length and weight of trucks be increased? A review of European research. Logistics Research Centre, HeriotWatt University, Edinburgh. In: Proceedings of the 13th International Symposium on Logistics 6-8 July 2008, Bangkok.

Negara D, Jayanti S, \& Widjasena B (2017) Analisis kecelakaan bus rapid transit (BRT) Semarang koridor II Terminal Terboyo-Terminal Sisemut Ungaran tahun 2016. Jurnal Kesehatan Masyarakat (e-Journal) 5 (5):115-125.

Oktavania (2014) Implementasi Pasal 14 Peraturan Daerah Provinsi Jawa Timur No 4 tahun 2012 tentang Pengendalian kelebihan Muatan. Malang: Universitas Brawijaya.

OECD, 2008. Towards Zero: Ambitious Safety Targets and the Safe System Approach. OECD, Paris.

Pratama MH (2015) Strategi Meningkatkan kualitas pelayanan publik (Studi deskriptif tentang strategi UPTD Pengujian Kendaraan Bermotor Tandes Kota Surabaya dalam meningkatkan kualitas pelayanan pengujian kendaraan bermotor). Kebijakan dan Manajemen Publik 3 (3):90-98.

Qi L, Zhou M, Luan W (2015) Emergency traffic-light control system design for intersections subject to accidents. IEEE Transactions on Intelligent Transportation Systems 17 (1):170-183.

Sugiyono (2009) Statistik Untuk Penelitian. Bandung: Alfabeta.

Trinca GW, Johnston IR, Campbell BJ, Haight FA, Knight PR, Mackay GM, McLean AJ, Petrucelli E, (1988). In: Reducing Traffic Injury - A Global Challenge. Royal Australasian College of Surgeons, Melbourne.

WHO (2004) World Report on Road Traffic Injury Prevention. WHO, Geneva. 